\title{
Development of Weaning Index on Islamic Community Based on Religion, Nutritional, and Psychological Aspect: A Qualitative Exploration
}

\author{
Ony Linda ${ }^{1}$, Imas Arumsari², Izza Rohman ${ }^{3}$ \\ ${ }^{I}$ Public Health Study Program, Faculty of Health Sciences, Universitas Muhammadiyah Prof. DR. HAMKA, Jakarta \\ ${ }^{2}$ Nutrition Study Program, Faculty of Health Sciences, Universitas Muhammadiyah Prof. DR. HAMKA, Jakarta \\ ${ }^{3}$ Mathematics Study Program, Faculty of Education, Universitas Muhammadiyah Prof. DR. HAMKA, Jakarta
}

*Corresponding author: imasarumsari@uhamka.ac.id

\begin{abstract}
This study aims to develop index of weaning based on religion, nutritional, and psychological aspect as the tool to assess the weaning behavior in the Islamic community. In-depth interview was conducted with experts of Qur'an, Hadits, nutrition, and psychology. This study was conducted on November 2019 - April 2020. Islam views exclusive breastfeeding and gradual weaning as a command from Allah swt and its implementation should consider support from both parents of the child. The command in Islam for 2 years of breastfeeding and gradually wean the baby is in line with the nutritional and psychological aspect. The recommendation to do the exclusive breastfeeding for 6 month and gradual weaning to solid food is related to the immunity, gastrointestinal and dental health, emotional bonding between mother and child, and training the child's independency. In the nutrition perspective, six-months period of breastfeeding and gradual weaning is beneficial for the baby, mother, father, and whole families in the household. Since Indonesia is the biggest Muslim population in the world, the weaning index developed from this study could be used as a tool to assess and design suitable health promotion program using religion-based approach.
\end{abstract}

Keywords: Health Promotion, Religion-based approach, Weaning.

\section{INTRODUCTION}

Infant mortality rate (IMR) still become a public health concern in the world, especially in Africa and Asia, including Indonesia [1]. One of the risk factors of infant mortality is weaken immune system which also leads to the infection. Improper weaning behavior, including early weaning or prolonged weaning affects poor immune system of infant [2]. Children aged 6-11 and 12-23 who were not breastfed had 1.8 and 2.0-times higher risk of mortality, respectively, compared to thos who were breastfed [3]. The term successful breastfeeding is closely related with the concept of exclusive breastfeeding which defined as no other food or drink, not even water, except breast milk (including milk expressed of from a wet nurse), for six months of life, but allows the infant to receive oral nutritional support, drops, and syrups of vitamins, minerals, and medicines [4]. Exclusive breastfeeding coverage in Indonesia is decreased along with the increasing age of the baby as published data showed that the coverage of exclusive breastfeeding according to age was $66 . \%(0-1$ month), 54.6\% (2-3 month), and 38.2\% (4-5 month) [5].

Recommendation for exclusive breastfeeding comes along with the gradual weaning. According to WHO, there is four principal aspects regarding to weaning practice. First, giving breast milk to the baby right after birth, second, give the breast milk up to 6 months of age, 
third, give complementary feeding after 6 months, fourth, continue breastfeed until 2 years age. However, the practice of giving proper weaning according to WHO guidance has not fully implemented as the data showed that breastfeeding coverage in Indonesia is decreased by the baby age [5]. The concept of weaning itself defined as the process when the baby is not breastfed anymore. This process can be related to several reasons, such as the mother stop to give breast milk, the baby did not want to be breastfed, or both of those factors.

There are several factors affecting early weaning, such as lack of support during breastfeeding period, difficulty in breastfeeding, breastfeeding duration shorter than 12 months in a previous pregnancy, and infant birth less than 2,300 gram [6]. There are reasons affecting difficulty in breastfeeding including insufficient milk supply, infants' behavior, and returning to work.

Since weaning and breastfeeding practice still become public health issue, especially in the developing countries, several approach of intervention have been applied to cope with this problem. However, study reported that a successful breastfeeding practice are not only affected by knowledge and attitude, but also culture, tradition, and support from the family [7]. Therefore, this study use religion based approach using qualitative exploration to develop tools for assessment of weaning behavior. This intervention model is in line with health promotion based on social ecological model which has been proved potential to change behavior [8]. This study aims to develop index of weaning based on religion, nutritional, and psychological aspect as the tool to assess the weaning behavior in the Islamic community. The weaning index developed from this study could be beneficial to assess the practice of weaning in the Islamic community for further intervention.

\section{RESEARCH METHOD}

This is a descriptive, qualitative, cross-sectional study applied purposive sampling to recruit informants through collaboration with experts from universities. The four experts were recruited from Universitas Muhammadiyah Prof. DR. Hamka (UHAMKA) and Universitas Indonesia (UI), Jakarta, Indonesia. Experts of Qur'an, Hadist, and Psychology were obtained from UHAMKA, while expert of maternal and child nutrition was obtained from UI. This study was conducted on November 2019 - April 2020.

Semi-structured and individual in-depth interviews were conducted with informants. Interview questions were designed according to critical point of weaning practice including optimum age of weaning, advantage of weaning in the optimum age for infant, mother, and families, negative impacts of weaning earlier or longer than the optimum age, and family support. The questions were designed to investigate the concept of each critical point from different perspective of expertise. Four interviews were conducted face to face in Bahasa Indonesia. Interviews were digitally recorded and lasted average for $1 \mathrm{~h}$.

Data were transcribed verbatim from the audio recordings of the interviews. Data was an iterative process between researchers. Any disagreements in the finding were adjudicated between researchers. The goal of data analysis was to elaborate the concept of each critical point from different perspective of expertise, therefore weaning index as the tool of assessment could be obtained from those critical point.

\section{Ethical consideration}

Ethical approval was obtained from Ethical Committee for Health Research, Universitas Muhammadiyah Prof DR. Hamka. Verbal consent were explained to the informant prior to the interview process.

\section{RESULTS AND DISCUSSION}

The results of this study will be discussed according to five critical aspects of weaning: (1) optimum age of weaning; (2) benefits of weaning in optimum age for infants, mother, and families; (3) negative impact of weaning earlier than optimum age for infants, mother, and families; (4) negative impact of weaning longer than optimum age for infants, mother, and families; (5) the criteria of family support during breastfeeding and weaning.

\subsection{Optimum age of weaning}

According to the expert of Qur'an, the optimum age of weaning is not usually at 2 years of age, can be less than 2 years of the age, which is 21 months, as it is considered deducting 2 years by the pregnant period ( 9 months).

In the point of view from expert of hadist and nutrition, the optimum age of weaning is exactly at 2 years of age. From the psychological perspective, the optimum weaning age is not earlier than 6 months, but no later than 2,3, or even 4 years of age.

\subsection{Benefits of weaning in optimum age for infants, mother, and families}

Qur'an views the optimum age for weaning as the ideal condition for infants. In the perspective of hadist, weaning in the optimum age can strengthening bone and muscle, building the foundation of physical growth and psychological development, bonding mother and baby, perfect timing for the child before adapting/copying to the environment, walk independently, and holding his/her own plate or glass. 
This concept is in line with the nutritional perspective as in the health perspective, 2 years of weaning is optimum for growth and development. In the psychological perspective, the optimum age is enough to wait until the child can be independent or ready, can built close relationship to parents, can support the baby to feel secure, to build cooperation with the surrounding environment, to build self-confidence and control.

In the Qur'an perspective, weaning in the optimum age represents the obedient towards Allah swt and it is an ideal condition for mom. Hadist also views weaning at optimum age can facilitate the mom to build emotional bonding with the child. It also facilitates mom to give first strength for the child.

Nutrition and health views weaning at optimum age is beneficial for mom as it is physiologically act as a natural contraception, therefore it can control birth. If the breastfeed practice applied correctly, it also can reduce body weight back to ideal weight. Meanwhile, in the psychological perspective, weaning at optimum age can be beneficial for mom to be mentally prepared for child fussiness during weaning period.

Weaning at optimum age not only beneficial for mom and child, but also for the whole family. Qur'an views weaning at optimum age as ideal condition for the whole family. It is supported by Hadist views, in the optimum age, the whole family can prepare child development easier and more measurable.

In the health perspective, weaning at optimum age gives chance for the whole family of the child to train his/her chewing ability. It is also good in the psychological perspective as weaning at optimum age will build close relationship in the whole family when the child get used to have meal together with family. It also reduces economic stress because family can save money from buying formula.

\subsection{Negative impact of weaning earlier than optimum age for infants, mother, and families}

Quran views earlier weaning does not always have negative impact because weaning related to the child ability and condition. In the hadist, it is explained that earlier weaning will cause insufficient nutrient and impairment of child emotional development. In the nutrition perspective, earlier weaning cause weaken immune system and the digestive system is not ready enough.

There are several impacts in the psychological aspect if the child was earlier weaned. There will be problem in the oral phase, which called as oral aggressiveness. In this condition, child cannot control food intake, which further leads to obesity. Another oral phase problem is the stagnation/fixed which showed by picky eating.

For the mother, earlier age of weaning will cause potential distance of emotional bonding between mother and child. Mother also need to give more effort to prepare food. In the psychological aspect, if the mother not ready enough to wean the baby, it can leads to depression and feeling useless. It also mentioned by Quran that wean the baby is a mutual agreement between both of parents, because when the family decide to wean the child, father should give proper financial support for both child and mom.

\subsection{Negative impact of weaning longer than optimum age for infants, mother, and families}

Prolonged breastfeeding or longer age of weaning also has negative impact. Nutrient intakes will not sufficient which resulting to under nutrition. In the psychological aspect, the child will miss important developmental step, such as the ability of self-regulation, confidence, and creativity.

Prolonged breastfeeding not only affect the child, but also the mother. The mom need higher nutritional requirement, higher than pregnant mom. It also affects self-dependency of the child, resulting to the more effort for mom to give her attention to the child.

\subsection{The criteria of family support during breastfeeding and weaning}

According to Quran, it is a mandatory for the child's father to give enough financial support for child and mom during breastfeeding and weaning period, even if they are divorce. The father also needs to make sure that the financial support is enough to fulfill the food intake of breastfeed mom more than usual condition (when she is not breastfeed). This is also supported by nutrition aspect that the nutritional need of breastfeed mom is higher than woman in usual condition. Psychological aspect sees the support from the family in including financial support and condition.

\subsection{Development of weaning index}

This study developed an index to assess weaning behavior according to results from the expert explained above. This index could be used as the tool for assessment and further intervention by using religionbased approach in Islamic community. 
Table 1. Weaning index developed from this study

\begin{tabular}{|c|c|c|c|}
\hline No & Question & Yes & No \\
\hline 1 & Did you practice breastfeeding because of Quran guidance? & & \\
\hline 2 & Did you practice breastfeeding because of Hadist guidance? & & \\
\hline 3 & Did you practice breastfeeding because of mother's health concern? & & \\
\hline 4 & Did you ever feel hurts because of breastfed? & & \\
\hline 5 & Did you practice breastfeeding because of mother's psychological condition concern? & & \\
\hline 6 & Did you ever feel mentally hurts because of breastfed? & & \\
\hline 7 & Did you practice breastfeeding because of child's health concern? & & \\
\hline 8 & Did you practice breastfeeding because of child's psychological condition concern? & & \\
\hline 9 & Did you wean when child aged $<21$ months old? & & \\
\hline 10 & Did you wean when child aged 21-24 months old? & & \\
\hline 11 & Did you wean when child aged 25-36 months old? & & \\
\hline 12 & Did you wean when child aged $>36$ months old? & & \\
\hline 13 & Did you breastfed the child by yourself? & & \\
\hline 14 & Did you ever give your child to be breastfed by another mom? & & \\
\hline 15 & $\begin{array}{l}\text { Did your husband and/or father of child give enough financial support to fulfill nutritional needs of } \\
\text { child and mother during breastfeeding process? }\end{array}$ & & \\
\hline 16 & $\begin{array}{l}\text { Did your husband and/or father of child give enough financial support to fulfill psychological needs } \\
\text { of child and mother during breastfeeding process? }\end{array}$ & & \\
\hline 17 & $\begin{array}{l}\text { Did your husband and/or father of child give enough financial support to fulfill needs for clothes of } \\
\text { child and mother during breastfeeding process? }\end{array}$ & & \\
\hline 18 & $\begin{array}{l}\text { Did your husband and/or father of child give enough financial support to fulfill needs for access for } \\
\text { information and health service of child and mother during breastfeeding process? }\end{array}$ & & \\
\hline
\end{tabular}

The results from this study showed that optimum weaning age is at 2 years of age according to informants from Quran, hadist, nutrition, and psychology experts, even though it was found some notes regarding to that optimum age according to Quran and psychology expert. Those noted are informed and also being consideration at defining the optimum age of weaning because different aspect has different rationale at deciding that optimum age.

The results from this study is in line with the previous study reported that weaning at 2 years of age is beneficial for the child, mom, and whole families [9-12]. Negative impact caused by early weaning, according to Quran expert, is not always considered as negative since breastfeeding practice needs consents and supports from both parents of the child and whole family [13-15]. It considers ability from the mother to breastfed and whole family to support. Early weaning could be considered to have a positive impact if it was done fulfilled consents and agreement to do so by both of the parents and whole families, even though other experts explained it might not beneficial for the growth and development. Child who was early weaned might not be ready for complementary foods $[16,17]$, and if it was done without the mother's consent, it might leads to mother's unpreparedness to give complementary foods [18].

Negative impact to the child, mother, and whole families might be occurred at not only early age of weaning, but also at prolonged breastfeeding or late age of weaning. Children who were late weaned are prone to 
have problem on growth and development as shown by studies from several developing countries [19-21]. Children with prolonged breastfeeding will not receive sufficient nutrient content from the breastmilk [21]. According to the results of this study, prolonged breastfeeding also inhibits the mother to do other activities. Meanwhile, according to hadist perspective, there is no negative impact of prolonged breastfeeding to the child because the bonding will always be maintained.

Family support also plays role on the breastfeeding and weaning practice. Husband role to give proper financial support during breastfeeding practice is crucial. It is supported by the result from previous studies showed that husband support for giving proper nutrition supply to both mother and child, support for giving access to information, and support for accessing health care is important for the successful breastfeeding until weaning practice [22, 23]. Giving the breastfeeding process to another mom could be an alternative if the mother found difficulties on doing breastfeeding, even though, emotional boding will not be developed as optimum as direct breastfeeding.

\section{CONCLUSION}

Different aspects of expertise in this study (Quran, hadist, nutrition, and psychology) views similar concept of weaning based on four critical point: optimum age of weaning; benefits of weaning in optimum age for infants, mother, and families; negative impact of weaning earlier than optimum age for infants, mother, and families; negative impact of weaning longer than optimum age for infants, mother, and families; and the criteria of family support during breastfeeding and weaning. Results from this study were elaborated into an index that could be used as the tool for assessment and further intervention by using religion-based approach in Islamic community.

\section{REFERENCES}

[1] WHO, "World Health Statistics," WHO, Geneva 2015.

[2] J. Beaumont, J. Montgomery, J. Buckberry, and M. Jay, "Infant mortality and isotopic complexity: New approaches to stress, maternal health, and weaning," American journal of physical anthropology, vol. 157, pp. 441-457, 2015.
[3] M. J. Sankar, B. Sinha, R. Chowdhury, N. Bhandari, S. Taneja, J. Martines, et al., "Optimal breastfeeding practices and infant and child mortality: a systematic review and metaanalysis," Acta paediatrica, vol. 104, pp. 3-13, 2015.

[4] W. H. Organization, "The optimal duration of exclusive breastfeeding: a systematic review," World Health Organization2001.

[5] B. P. Statistik, "Survei demografi dan kesehatan Indonesia 2017," Jakarta: Badan Pusat Statistik, 2017.

[6] F. C. F. Mikami, R. P. V. Francisco, A. Rodrigues, W. R. Hernandez, M. Zugaib, and M. de Lourdes Brizot, "Breastfeeding twins: Factors related to weaning," Journal of Human Lactation, vol. 34, pp. 749-759, 2018.

[7] E. M. M. Has, M. Syaltut, T. Kusumaningrum, and F. Efendi, "Early weaning food for infants (0-6 months old) in madurese people based on transcultural nursing theory," $E \& E S$, vol. 116 , p. 012059, 2018.

[8] J. Gregson, S. B. Foerster, R. Orr, L. Jones, J. Benedict, B. Clarke, et al., "System, environmental, and policy changes: using the social-ecological model as a framework for evaluating nutrition education and social marketing programs with low-income audiences," Journal of nutrition education, vol. 33, pp. S4-S15, 2001.

[9] J. Villar, R. Ochieng, E. Staines-Urias, M. Fernandes, M. Ratcliff, M. Purwar, et al., "Late weaning and maternal closeness, associated with advanced motor and visual maturation, reinforce autonomy in healthy, 2-year-old children," Scientific reports, vol. 10, pp. 1-27, 2020.

[10] I. Mupunga, P. Mngqawa, and D. R. Katerere, "Peanuts, aflatoxins and undernutrition in children in Sub-Saharan Africa," Nutrients, vol. 9, p. 1287, 2017.

[11] T. Kumar, S. Kumar, M. Kumar, and A. Sharan, "Study on Effects of Exclusive Breastfeeding on Immunity of Infants," Indian Journal of Public Health Research \& Development, vol. 7, pp. 300-303, 2016.

[12] D. R. Pangestuti, "Nutritional status of exclusive compared to non exclusive 
breastfeeding mother," Jurnal Gizi dan Pangan, vol. 13, pp. 11-16, 2018.

[13] D. R. Hasanah, N. K. Putri, and A. Y. Pramono, "Effectiveness of Forming Breastfeeding Support Group Program to Improve Exclusive Breastfeeding," Jurnal Administrasi Kesehatan Indonesia, vol. 8, 2020.

[14] C. Nsiah-Asamoah, D. T. Doku, and S. Agblorti, "Mothers' and Grandmothers' misconceptions and socio-cultural factors as barriers to exclusive breastfeeding: A qualitative study involving Health Workers in two rural districts of Ghana," PloS one, vol. 15, p. e0239278, 2020.

[15] S. Mulyani, "Pregnant women with extended family on knowledge, motivation, and readiness in exclusive breastfeeding," International Journal of Emerging Trends in Social Sciences, vol. 1, pp. 104-107, 2017.

[16] F. N. Were and C. Lifschitz, "Complementary feeding: Beyond nutrition," Annals of Nutrition and Metabolism, vol. 73, pp. 20-25, 2018.

[17] A. H. M. Lin and B. L. Nichols, "The digestion of complementary feeding starches in the young child," Starch-Stärke, vol. 69, p. 1700012, 2017.

[18] S. Jain, R. Thapar, and R. Gupta, "Complete coverage and covering completely: breast feeding and complementary feeding: knowledge, attitude, and practices of mothers,"
Medical Journal Armed Forces India, vol. 74, pp. 28-32, 2018.

[19] N. Cetthakrikul, C. Topothai, R. Suphanchaimat, K. Tisayaticom, S. Limwattananon, and V. Tangcharoensathien, "Childhood stunting in Thailand: when prolonged breastfeeding interacts with household poverty," BMC pediatrics, vol. 18, p. 395, 2018.

[20] B. Syeda, K. Agho, L. Wilson, G. K. Maheshwari, and M. Q. Raza, "Relationship between breastfeeding duration and undernutrition conditions among children aged 0-3 Years in Pakistan," International Journal of Pediatrics and Adolescent Medicine, 2020.

[21] M. Czosnykowska-Łukacka, B. KrólakOlejnik, and M. Orczyk-Pawiłowicz, "Breast milk macronutrient components in prolonged lactation," Nutrients, vol. 10, p. 1893, 2018.

[22] T. Thepha, D. Marais, J. Bell, and S. Muangpin, "Perceptions of northeast Thai breastfeeding mothers regarding facilitators and barriers to six-month exclusive breastfeeding: focus group discussions," International breastfeeding journal, vol. 13, p. 14, 2018.

[23] M. Mirghafourvand, M. Kamalifard, F. Ranjbar, and N. Gordani, "Relationship of breastfeeding self-efficacy with quality of life in Iranian breastfeeding mothers," The Journal of Maternal-Fetal \& Neonatal Medicine, vol. 31, pp. 2721-2728, 2018. 